\title{
ALMEIRÃO, QUICÚIO E GRAMA SEDA COMO ALIMENTO VERDE PARA PINTOS EM CRESCIMENTO $(*)$
}

\author{
A. P. TRIVELIN \\ Assistente \\ Escola Superior de Agricultura "Luiz de Queiroz" \\ Universidade de São Paulo
}

TNIMI:H:

10 - Bibliografia $\ldots \ldots \ldots \ldots$

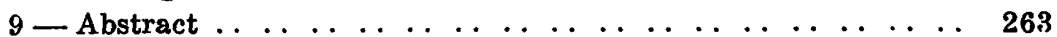

8 - Agradecimento . . . $\ldots \ldots \ldots \ldots \ldots$

7 - Resumo e conclusões . . . . . . . . . . . . . . . . . . 262

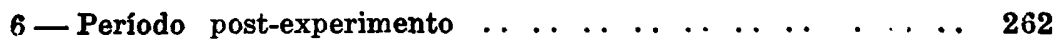

5 - Análises, resultados e discussão $\ldots \ldots \ldots \ldots$

4 - Material e método . . . . . . . . . . . . . . . . . . 258

3 - Almeirão, quicúio e grama seda . . . . . . . . . . . . 258

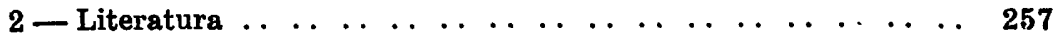

1 - Introdução $\ldots \ldots \ldots \ldots$

(*) Trabalho da 14a. Cadeira - 2a. de Zootecnia, apresentado à II Reunião Interamericana de Produção Animal realizada em Baurú (8-19/12/1952). 


\section{1 - INTRODUÇÃO}

A alimentação constitui na exploração avícola problema de primordial importância. Pois, é sabido que para os pintos experimentarem desenvolvimento rápido e econômico ou para as poedeiras terem boa postura é necessário que recebam uma alimentação adequada e conveniente.

A ração balanceada ou equilibrada formada à base de grãos e farelos pode apresentar certas deficiências em algumas vitaminas e minerais essenciais ao crescimento. Por este motivo, constitui regra geral fornecer às aves, principalmente para as que se acham em crescimento, uma suplementação verde, on de elas possam encontrar um complemento destes principios nutritivas.

$O$ seu emprêgo justifica-se por constituir o alimento melhor suprido de todas vitaminas indispensáveis ao crescimentc e à vida normal destas aves. Os alimentos verdes apresentam sempre maior valor nutrítivo quando novos, porque revelam maior porcentagem de proteinas e de vitaminas, em particular de ribc flavina.

São utilizados como fonte de vitamina A, embora, em alguns casos seja mais proveitoso o fornecimento do óleo de fígado de bacalhau, certas raízes ou verdes na forma dessecada (feno) como suplemento daquela fornecida pelo milho amarelo (1) Esta vitamina apresenta-se na forma de caroteno (pró-vitamina A) e o seu teor está relacionado à coloração verde. Atinge o máximo nas plantas novas, diminui com o florescimento, e mais ràpidamente, com o seu amarelecimento. Apenas, não fornecem a vitamina $D$ que é assegurada pelos raios ultra-violetas da luz solar.

ELVEHJEM e SOBER, citados por HEUSER, relatam que os alimentos verdes são ricos, não sòmente em princípios nutritivo: bem conhecidos, como também, em outros fatores desconhecidos; revelam quantidades importantes de caroteno (próvitamina $\mathrm{A}$ ), vitamina $\mathrm{C}$, vitamina $\mathrm{K}$, tiamina, riboflavina (vitamina G), piridoxina, ácido pantotênico, niacina, biotina e colina.

Os alimentos verdes apresentam teor mineral satisfatório e o proteico variável, podendo, às vezes ir até $30 \%$ (3). Admi te-se que atuem com o verdadeiro estimulante do apetite $\mathrm{e}$ comı preservador da saúde, o que é revelado pelo melhor aproveitamento dos alimentos e menor mortalidade. São dotados de qualidades laxativas que conferem ao aparelho digestivo das aves condições para seu normal funcionamento. Embora, 
o sulfato de magnésio (6) possa ser empregado com esta finalidade, os resultados obtidos com os alimentos verdes são sempre melhores.

\section{2 - LITERATURA}

Os pintos apresentam 2 períodos de crescimento: (a) desde o nascimento até a idade de 7-10 semanas, durante o qual são criados em criadeiras e casas adequadas (pinteiros) e (b) desde esta idade até 24 semanas, período este, em que permanecem em parques gramados.

Na literatura americana vamos encontrar grande númerc de trabalhos realizados durante o segundo período de crescimento, visando, com liberal fornecimento de forragens verdes. maicr economia de alimentos. Assim, STEPHENSON e KENNARI relatados por (4) demonstraram que neste segundo período os franguinhos poderão apresentar bons aumentos de pê. so, com alimenios simples e baratos, como milho ou trigo e minerais, desde que tenham acesso às boas pastagens. A Estação Experimental de Ohio (4) iniciou em 1940 estudo neste senti do, pesquizando novas rações e métodos de alimentação a chegaram a resultados, segundo os quais, franguinhos, em pastagem de trevo Ladino conseguiram bons aumentos de pêso com rações de $12 \%$ e $14 \%$ de proteinas.

Verificaram posteriormente, que uma ração formada de milho e minerais (*) oferecia os mesmos resultados que àquelas de $12 \%$ e $14 \%$ de proteinas. Concluiram que estas rações, usadas como suplemento do trevo Ladino tinham por função primordial o fornecimento de sais minerais e não de proteinas como se fazia supor. Isto, deixa evidente a importância de uma boa alimentação verde.

As aves, no primeiro período de crescimento, necessitam de maicr quantidade de nutrientes e embora, alimentadas convenientemente, requerem uma suplementação verde, para compensar as deficiências de minerais e vitaminas existentes nas rações, pràticamente, balanceadas. Os alimentos verdes proporcionam melhor volume à razão e devem ser considerados de inestimável valor quando se usam alimentos concentrados (6) .

Não obstante, TAYLOR, RUSSELL and PLATT (10) e o trabalho (14) citado por HEUSER (3) revelam que os pintos podem experimentar desenvolvimento normal com boas ra-

(*) Farinha de ossos degelatinados, sal, farinha de ostra e areia. 
ções isentas de alimentação verde. SMITH and JOHNSON (9) também concluiram que a proporção de crescimento dos pintos durante as 10 primeiras semanas não foi alterada em 2 casos : (a) pela adição de alimento verde usado como suplemento de uma ração básica e (b) pela substituição da farinha de feno de alfafa pela farinha de folhas de alfafa desidratada.

\section{3 - ALMEIRÃO, QUICÚIO E GRAMA SEDA}

Contamos com grande número de forragens verdes para alimentação das aves. A Seção de Avicultura deste estabelecimento, desde muito tempo tem utilizado o almeirão de folha larga (Chicorium intybus L.) como fonte de verde para suple mentação das rações para pintos em crescimento e com ótimos resultados. Trata-se de uma hortaliça de excelentes qualidades, qu$: \in$ fornece um corte por mês e produz durante o ano todo (11).

Não obstante a facilidade de sua cultura procuramos ensaiar as boas qualidades de dois outros suplementos verdes o quicúio e a grama seda.

() primeiro deles, o quicúio (Pennisetum clandestinum Hochst) tem sido reputado como umas das gramineas mais ricas, apresentando um teor de proteina que algo se aproxima do da alfafa, principalmente, quando nova. Pode ser cultivado para corte (11) durante o ano todo, nas mesmas condições daquela legumincsa. Desde que se trate de um terreno adubado, de solo fresco ou irrigado, poderá oferecer alguns cortes com abundância de forragem verde. $O$ almeirão e o quicúio foram classificados (11) como forragens capazes de produzir verde durante $\mathrm{c}$ ano todo, sendo considerado o almeirão como produtor de melhores resultados.

A grama seda (Cynodon dactilon Pers.) dada suas ótimas qualidades forrageiras foi empregada a fim de ser comparadz com as duas precedentes.

A composição química destes alimentos verdes, figura no Quadro I, e as análises foram feitas no laboratório de Química Agricola, deste Estabelecimento de ensino pelo analista Armando Porta.

\section{4 - MATERIAL E MÉTODO}

Com a finalidade de ensaiarmos a influência do verde como alimento capaz de influir no crescimento, quando utilizado como suplemento de ração para pintos, reunimos em 4 lotes. 
pintos da raça LEGHORN BRANCA, perfazendo um total de 40 aves para cada um $\left(^{*}\right)$.

Os pintos nasceram em 18-10-949 e sòmente em 31 do mesmo mês é que formamos os lotes, de maneira que estes foram integrados por aves que apresentavam 13 dias de idade. Assim pudemos eliminar todas aquelas que se mostravam fracas e que sem dúvida alguma viriam constituir fonte de variação Embora, tal critério fosse considerado, os 4 lotes do experimento foram formadios por pintos escolhidos ao acaso.

Como a separação do séxo na citada raça, em pintos ainda novis constitui uma operação que requer muita prática, fizemos a separaçãe dos machos e das femeas na última pesada, levando em consideração a emplumação $\epsilon$ desenvolvimento da crista. As aves foram numeradas, de maneira que pudemos considerar seu cesenvolvimento individual.

A ração usada foi a mesma para os 4 lotes, apenas diferin do pela suplementação verde, uma vez que desejávanics observar sua influência sôbre o tratamento sem verde e comparar os desenvolvimentos obtidos com o emprêgo dos diferentes suplementos.

Suplementamos três lotes, com almeirão (A), quicúio (Q) e grama seda (GS). O quarto, deixamos sem suplementação (SV) para servir como testemunha. Estes verdes foram colhidos sempre de um mesmo local e no estado tenro. Foram cortados a pequenas dimensões e ministrados uma vez ao dia.

Inicialmente, fornecemos 200 gramas por dia para cada lote, o que corresponde 5 gramas por cabeça. Este pêso foi aumentado gradativamente, conforme se fez necessario, até 600 gramas, nos últimos dias, o que deu, pràticamente, uma média diária de 15 gramas por cabeça.

Embura, estes alimentos verdes fossem colhidos em estado tenro a grama seda apresentava coloração mais escura e por ter as folhas mais estreitas, depois de picada, dava impressão de ser menos apetecida que o quicúio, que era de coloração mais clara e de folhas mais largas. Este último revelava nestas condiçi)es aspecto menos apetecivel que o almeirão.

Aliado à estas observações constatamos maior preferência pelo almeirão, seguindo o quicúio e finalmente, a grama seda. De início não observamos esta preferência, provàvelmente, devido a pequena quantidade de verde fornecida.

(*) Durante a primeira semana do experimento morreu 1 pinto nos lotes $\mathrm{Q}, \mathrm{GS} \in \mathrm{SV}$. Resolvemos elimina-los da 1a. pesada, motive pelo qual, para efeito de análise computamos apenas 39 aves. 
Ela toi considerada tomando por base a sobra verificada nos cochos, o que foi maior no lote grama seda, menor no quicúio e não restando nada no lote almeirão durante tôda a experiência.

No Quadro III estão reunidas as exigências fornecidas por RECOMENDED NUTRIENT ALLOWANCES FOR POULTRY, por quilo de alımento, para pintos de 0-8 semanas de idade $\epsilon$ no Quadro II, a ração utilizada com sua provável riqueza em vitaminas. Para o cálculo dessa riqueza tomamos por base os dados fornecidos por MORRISON (7) e embora, não seja rigorosamente igual áquela dos alimentos empregados, serve para orientar nossas conclusões. Vemos que a ração foi formulada, pràticamente, com o mesmo teor protéico (19\% em vez de $20 \%)$ e que apresenta pequena deficiência em vitamina A e ribofla vina. Sua relação $\mathrm{Ca} / \mathrm{P}$ é $1,5 / 1$ que é considerada boa para pintos em crescimento (12).

\section{5 - ANALISES, RESULTADOS E DISCUSSÃO}

Os pintos foram pesados semanalmente e no Quadro IV, temos reunidos os valores das médias, erros e erros das médias.

A grosso modo temos impressão pelo exame daquelas, que o almejrão proporcionou melhores resultados que o quicúio e grama seda. Embora, a média do lote almeirão fosse na primeira pesada inferior de 1,7 gramas à do lote grama seda, na sexta pesada que foi a última deste experimento, ela a superou de 40,4 gramas. A média do lote quicúio classificou-se entre as do almeirão e grama seda.

Empregamos o t-teste para compararmos estas médias e os resultados estão expressos no Quadro V. Por ele, vemos que sem a separação de sexo, a significância estatistíca, entre as do almeirão e sem verde, verificou-se a partir da 3a. pesada e da 4a. e 5a., respectivamente, quando comparamos as médias do quicúio e grama seda com as do lote sem verde (testemunha).

Estatisticamente, não houve diferença entre o almeirão e o quicúio, e entre este e a grama seda. Comparando as médias dos lotes almeirão e grama seda, os valores de $t$ mostraram-se duvidosos e na 4a., 5a. e 6a. pesada.

Como us pintos foram numerados fizemos a separação dos machos e das femeas (Quadro VI) e procuramos comparar o desenvolvimento experimentado por estes dentro do mesmo tratamento (Quadro VII). Vemos que no lote suplementado pelo almeirão, tanto as femeas como os machos apresentaram desen- 
rolvimento majs ou menos semelhante, pois, sòmente constatamos diferença significativa na 6a. pesada e duvidosa na 5a. . O messrio se deu com os pintos suplementados pela grama seda. No lote que recebeu o quicúio os machos e as femeas, tiveram desenvolvimento idêntico, não se registrando, estatisticamente, nenhuma diferença. Finalmente, no lote sem suplerıentação esta significância apareceu a partir da $3 a$. pesada.

Os valores de t provenientes da comparação das médias dos macho: (Quadro VIII) mostram-nos que com a suplementação de quicúio e grama seda eles não apresentaram melhor desenvolvimento que àqueles do lote sem verde. Ainda, que estes suplernentos muito se aproximaram do almeirão que se comportou algo superior, visto ser estatisticamente significante na 6 a. pesada $\odot$ duvidoso na 5a. quando foi comparado ao lote testemunha.

No Quadro IX temos reunidos os valores de $t$ resultartes da ccimparação entre as médias das femeas e por ele observamos que as femeas do lote almeirão estatisticamente, mostraram-se superiores às do lote sem verde, desde a $3 a$. pesada. As do quicúio e grama seda, sòmente, a partir da 4a. pesada revelaram-se superiores. Não constatamos diferença entre as femeas des lotes suplementados com almeirão, quicúio e grama seda.

Pelo exposto vemos que apenas constatamos diferença na 6a. pesada entre os machos dos lotes almeirão e sem verde, e não verificamos entre os machos deste último lote e àqueles dos lotes suplementados com quicúio e grama seda. As femeas dos lotes suplementados apresentaram desenvolvimento superior às du lote sem verde. Assim, a diferença estatística observada entre machos e femeas, sòmente, pode ser atribuida ao pouco desenvolvimento destas.

Para melhor concluirmos fizemos eliminação de duas fe. meas, uma do lote grama seda (pinto 987) e outra no de quicúio (pinto 1030), cujos pêsos estavam muito abaixo da média e procedemos a nova análise. Os novos valores de $t$ (Quadro $\mathrm{X})$, sem separação de sexo, vieram confirmar os resultados anteriores, apenas revelando significância entre grama seda sem verde, a partir da 4a. pesada, em vez de duvidoso como foi anteriormente verificado (Quadro V).

Comparando as médias das fêmeas dos lotes suplementados, após as flıminações, vemos que elas apresentaram igual desenvolvimenio. Com relação ao lote sem verde, elas se mostraram superiores (Quadro XI) desde a 3a. pesada.

Os valores de $t$, oriundos da comparação das médias dos machus e das fémeas no lote quicúio, confirmaram plenamente 
os resultados do Quadro VII. No lote grama seda, mostraramse duvidosos - 2,09 e 2,52 - na 5a. e 6a. pesada, respectivamente, em vez de duvidoso e significante como foram anteriormente constatados (Quadro VII).

\section{6 -. PERIODO POST-EXPERIMENTO}

Depois da sexta pesada, todos os 4 lotes passaram a receber o almeirão como suplemento verde. Não obstante, verificamos entre os pintos do lote sem verde, uma mortalidade muito elevada como consequência provável da deficiência de vitamina $A$, riboflavina e sais minerais, pois, após a última pesada eles se revelavam assaz prejudicados.

Abaixo, reunimos o número de mortes ocorridas durante o experimento e rieste período, que teve duração aproximada de 15 dias. Vemos que a mortalidade verificada pode ser considerada normal nos lotes suplementados e anormal no lote sem verde.

Tratamentos

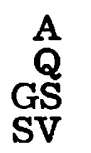

N. de mortes

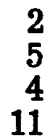

$\%$

5,0

12,5

10,0

27,5

\section{7 - RESUMO E CONCLUSÕES}

Reunimos 160 pintos da raça LEGHORN BRANCA em 4 lotes de 40. Estes lotes estiveram submetidos às mesmas condições experimentais, apenas, diferindo na suplementação verde - almeirão (A), quicúio (Q), grama seda (GS) e sem verde (SV). Os pintos que os constituiram foram numerados e pesados semanalmente. A separação do séxo foi feita na 6a. pesada pela emplumação e desenvolvimento da crista (48 dias de idade) Os dados colhidos e analizados permitem-nos as seguintes conclusões :

1. - Os pintos dos lotes suplementados com almeirão, quicúio a grama seda revelaram melhor desenvolvimento que àquele:s do não suplementado (testemunha) e esta superioridade deu-se a partir da 3a. pesada para o almeirão e da 4a. pare o quicúio e grama seda (Quadro X). A mortalidade verificada, incluindo $n$ período post-experimento, pode ser considerada normal nos lotes suplementados e elevada $(27,5 \%)$ no lote sem. verde 
2. - O almeirão revelou-se algo superior ao quicúio e a grama seda, podendo estes últimos serem admitidos num mesmo plano (Quadro X).

3 - Os suplementos verdes utilizados, pouca influência apresentaram no desenvolvimento dos machos. Apenas constatamos significância, entre os dos lotes almeirão e sem verde, na 6a. pesada, que foi a última deste experimento. Nas demais comparações (Quadro VIII) os machos revelaram igual crescimento.

4 - As fêmeas dos lotes suplementados com almeirão, quicúio e grama seảa, mostraram-se superiores àquelas do lote sem verde desde a 3a. pesada (Qudro XI), o que vem indicar a influência da alimentação verde empregada no crescimento destas.

Acreditamos, em face de alguns resultados já obtidos (13), que a causa determinante desta superioridade resida no fato dos alimentos verdes utilizados encerrarem princípios que tenham ação sôbre a função hormonal das fêmeas.

\section{8 - AGRADECIMENTO}

Agradecemos ao Prof. Alcides Di Paravicini Torres pelas críticas formuladas e ao Armando Porta, pela confecção das anćljses químicas das forragens verdes empregadas.

\section{9 - ABSTRACT}

The author studied in this paper effect of chicory (Chicoriuri intybus L.), kikuyugrass (Pennisetum clandestinum Hochst) and a variety of Bermuda grass (Cynodon doctilon Pers.) named "Grama seda" as green feeds in growth of White Leghorn chickens (0-8 weeks). Males and females were separeted by feathering and development of comb.

The results obtained can be summarized as follows :

a) - Withcut separation of sex, the chickens that received green feeds showed better development than that did not receive green suplements.

b) - The chicory showed to be something better that kikuyugrass and Bermuda grass, which had a similar effect.

c) - The green feeds used had little influence in develupment of males.

d) - The females in the lots suplemented by green feeds showed to be superior to the females in the lots that did rot receive it. 
e) - The author think that the presence of some priciples having action in the female hormony function is responsable for the better growth in the lot that received green feeds.

\section{0 - BIBLIOGRAFIA}

1-EWING, W. RAY., 1951 - Poultry nutrition. 4a. Ed. Rev. South Passadena, California.

2-GRANER, E. A., 1952 - Como aprender estatística. Edições Melhoramentos. São Paulo.

3 - HEUSER, G. F., 1946 - Feeding poultry. John Wiley \& Sons. New York.

4-HUGHES, H. D., HEATH, M. E. and METCALFE, D. S., 1951 - Forragens. The Iowa State College Press.

5 -- JARDIM, W. R. e A. P. TRIVELIN., 1947 - A influência da alimentação verde na postura. Anais da E. S. A. "Luiz de Queiroz" 4: 452-457. Piracicaba.

6-LAMON, H. M., and A. R. LEE., 1929 - Poultry feeds and feeding. O. Judd. New York.

7-MORRISON, F. B., 1950 - Feeds and Feeding. 21a. Edition Unabr. Ithaca. New York.

8- O'TERO, JOSE' RAMOS., 1946 - O capim quicúio. 2a. Ed. S. I. A. Ministério da Agricultura. Rio de Janeiro.

9. - SMITH, R M. and S. R. JOHNSON., 1941 - The effect of green suplement on chick growth. Poultry Sci. 20: 473.

10 - TAYLOR., M. W., W. C. RUSSELL, and C. S. PLATT., 1944 - The value of grass clippings silage for the growing chick. Poultry Sci. 23: 213.

11 - TORRES, A. DI PARAVICINI, 1947 - Alimentação dos marrecos 1. Forragem verde. Anais da E. S. A. "Luiz de Queiroz" 4: 268-275. Piracicaba.

12 - Torres, A. DI PARAVICINI, 1949 - Alimentação das aves. Noções práticas. Ed. Melhoramentos. São Paulo.

13 - VEIGA, J. S. e RIBEIRO, O. F., 1951 - Estrogênios em plantas forrageiras e seu possível efeito sôbre a fertilidade dos rebanhos nacionais nos períodos das águas e da sêca. (Nota prévia). Anais do V Congresso Brasileiro de Veterinária. São Paulo.

14 , What is the value of lawn clippings silage in poultry feeding? N. J., Rept - 1941-1942-30. 


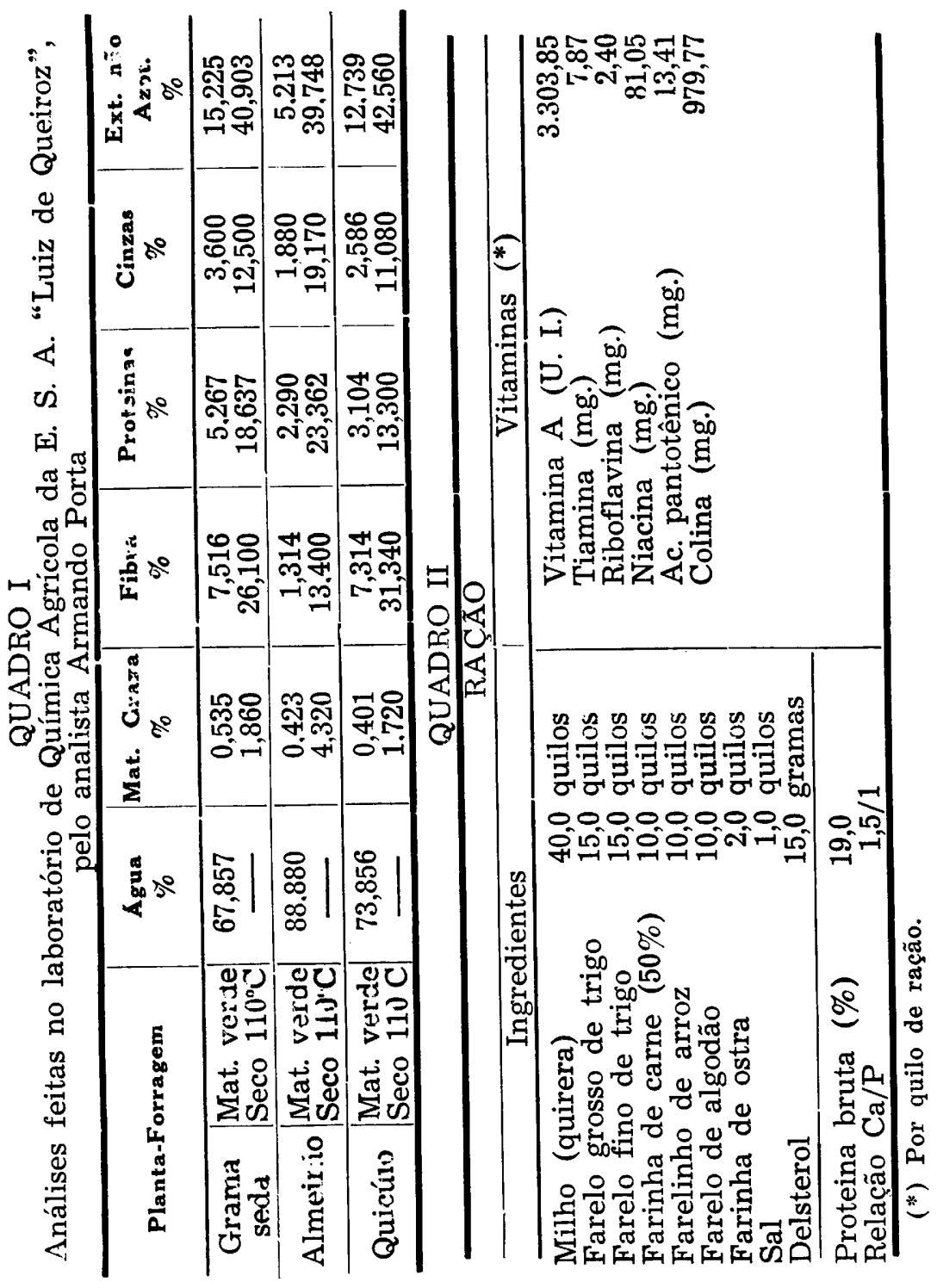




\section{QUADRO III}

Exigência para pintos de 0-8 semanas segundo RECOMMENDED NUTRIENT ALLOWANCES FOR POULTRY, por quilo de alimento

\begin{tabular}{lr}
\hline Proteina total (\%) & 20,0 \\
\hline Vitaminas & \\
Vitamina A (U. I.) & $4.400,00$ \\
Vitamina D (U. A. O. A. C.) & 396,00 \\
Tiamina (mg.) & 1,98 \\
Riboflavina (mg.) & 3,52 \\
Ac. pantotênico (mg.) & 11,00 \\
Ac. nicotínico (mg.) & 17,60 \\
Piridoxina (mg.) & 3,52 \\
Biotina (mg.) & 0,099 \\
Colina (mg.) & $1.540,00$ \\
Minerais & \\
Cálcio (\%) & 1,0 \\
Fósforo (\%) & 0,6 \\
Sal (\%) & 0,5 \\
Manganês (\%) & 55,0 \\
lodo (mg.) & 1,1 \\
\hline
\end{tabular}

QUADRO IV

\begin{tabular}{|c|c|c|c|c|c|}
\hline Pesadas & $\begin{array}{l}\text { Trata- } \\
\text { mentos }\end{array}$ & n & $x$ & - & $3 \bar{x}$ \\
\hline 1a. & $\begin{array}{l}\text { A } \\
\text { Q } \\
\text { GS } \\
\text { SV } \\
\end{array}$ & $\begin{array}{l}40 \\
39 \\
39 \\
39 \\
\end{array}$ & $\begin{array}{l}77,3 \\
78,1 \\
79,0 \\
77,8\end{array}$ & $\begin{array}{l}7,80 \\
9,35 \\
8,85 \\
9,39\end{array}$ & $\begin{array}{l}1,23 \\
1,49 \\
1,42 \\
1,50\end{array}$ \\
\hline $2 a$. & $\begin{array}{l}\mathbf{A} \\
\mathbf{Q} \\
\text { GS } \\
\text { SV } \\
\end{array}$ & $\begin{array}{l}40 \\
39 \\
39 \\
39 \\
\end{array}$ & $\begin{array}{l}108,5 \\
107,0 \\
109,0 \\
106,2\end{array}$ & $\begin{array}{l}14,55 \\
16,13 \\
14,38 \\
16,64 \\
\end{array}$ & $\begin{array}{l}2,30 \\
2,58 \\
2,30 \\
2,66 \\
\end{array}$ \\
\hline 3a. & $\begin{array}{l}\text { A } \\
\text { Q } \\
\text { GS } \\
\text { SV } \\
\end{array}$ & $\begin{array}{l}40 \\
39 \\
39 \\
39 \\
\end{array}$ & $\begin{array}{l}161,3 \\
154,9 \\
154,8 \\
146,2 \\
\end{array}$ & $\begin{array}{l}23,26 \\
26,70 \\
23,24 \\
27,97\end{array}$ & $\begin{array}{l}3,68 \\
4,28 \\
3,72 \\
4,48 \\
\end{array}$ \\
\hline 4a. & $\begin{array}{l}\mathrm{A} \\
\mathbf{Q} \\
\text { GS } \\
\text { SV } \\
\end{array}$ & $\begin{array}{l}40 \\
39 \\
39 \\
39 \\
\end{array}$ & $\begin{array}{l}230,5 \\
216,9 \\
213,4 \\
191,8 \\
\end{array}$ & $\begin{array}{l}32,33 \\
36,45 \\
33,08 \\
43,00 \\
\end{array}$ & $\begin{array}{l}5,12 \\
5,84 \\
5,30 \\
6,89 \\
\end{array}$ \\
\hline 5a. & $\begin{array}{l}\mathbf{A} \\
\mathbf{Q} \\
\text { GS } \\
\mathbf{S V}\end{array}$ & $\begin{array}{l}39 \\
39 \\
39 \\
38 \\
\end{array}$ & $\begin{array}{l}309,7 \\
299,1 \\
288,0 \\
250,8\end{array}$ & $\begin{array}{l}46,71 \\
52,53 \\
49,72 \\
64,68\end{array}$ & $\begin{array}{r}7,49 \\
8,42 \\
7.97 \\
10,50\end{array}$ \\
\hline 6a. & $\begin{array}{l}\text { A } \\
\text { Q } \\
\text { GS } \\
\text { SV }\end{array}$ & $\begin{array}{l}36 \\
39 \\
39 \\
38 \\
\end{array}$ & $\begin{array}{l}398,3 \\
374,2 \\
357,9 \\
299,7\end{array}$ & $\begin{array}{l}69,44 \\
70,08 \\
70,43 \\
83.66\end{array}$ & $\begin{array}{l}11.57 \\
11,23 \\
11.29 \\
13,58\end{array}$ \\
\hline
\end{tabular}




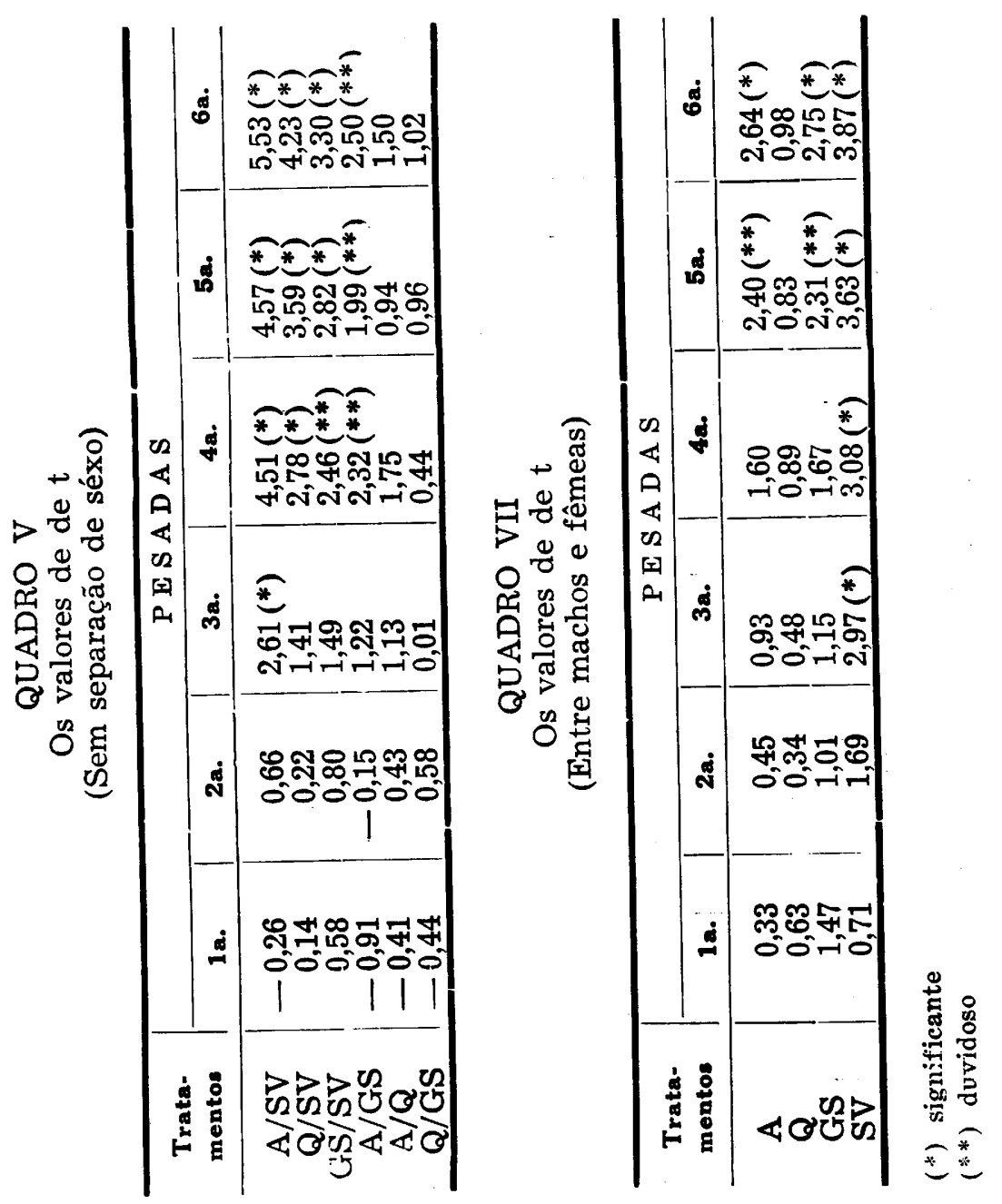




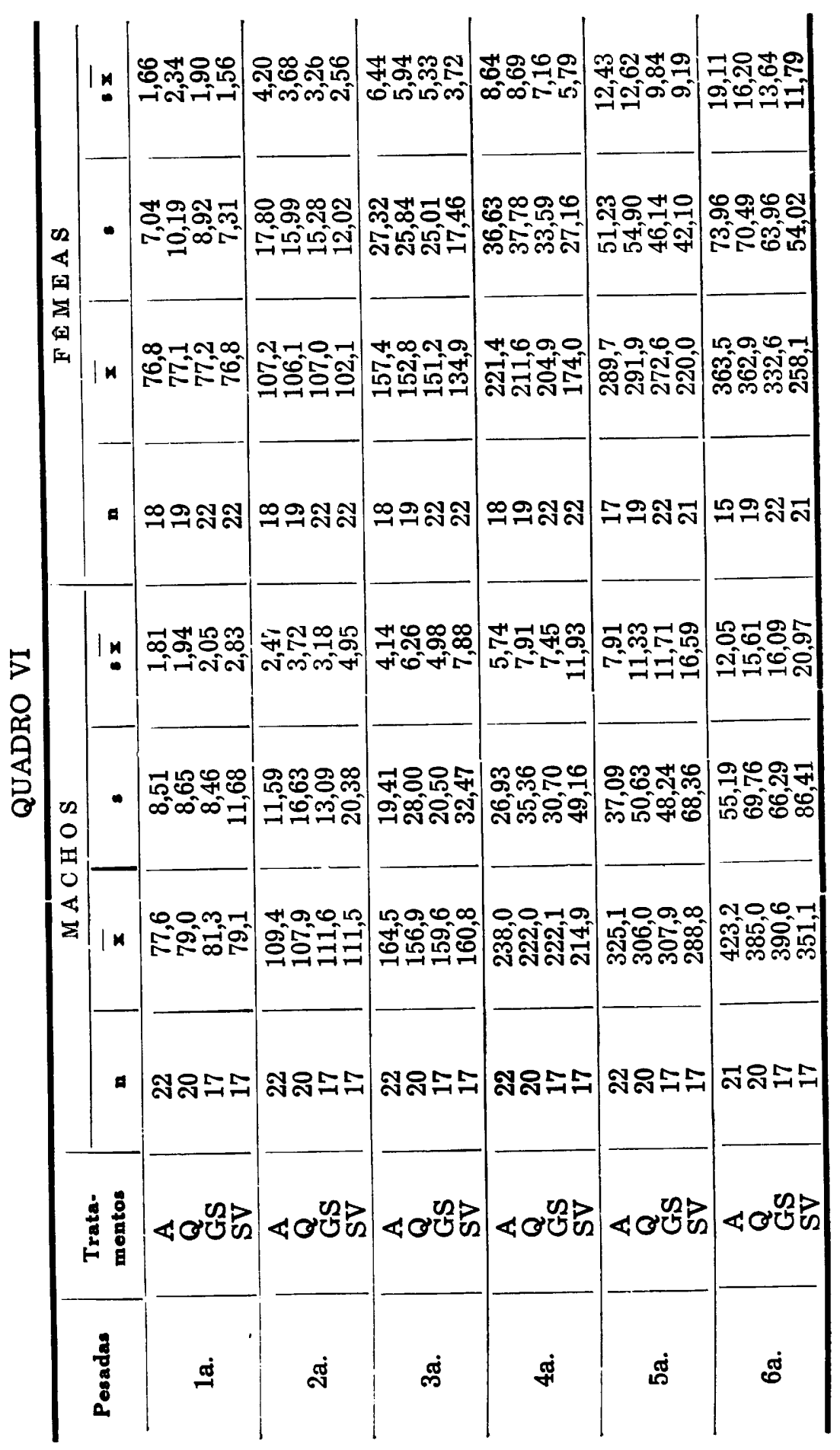




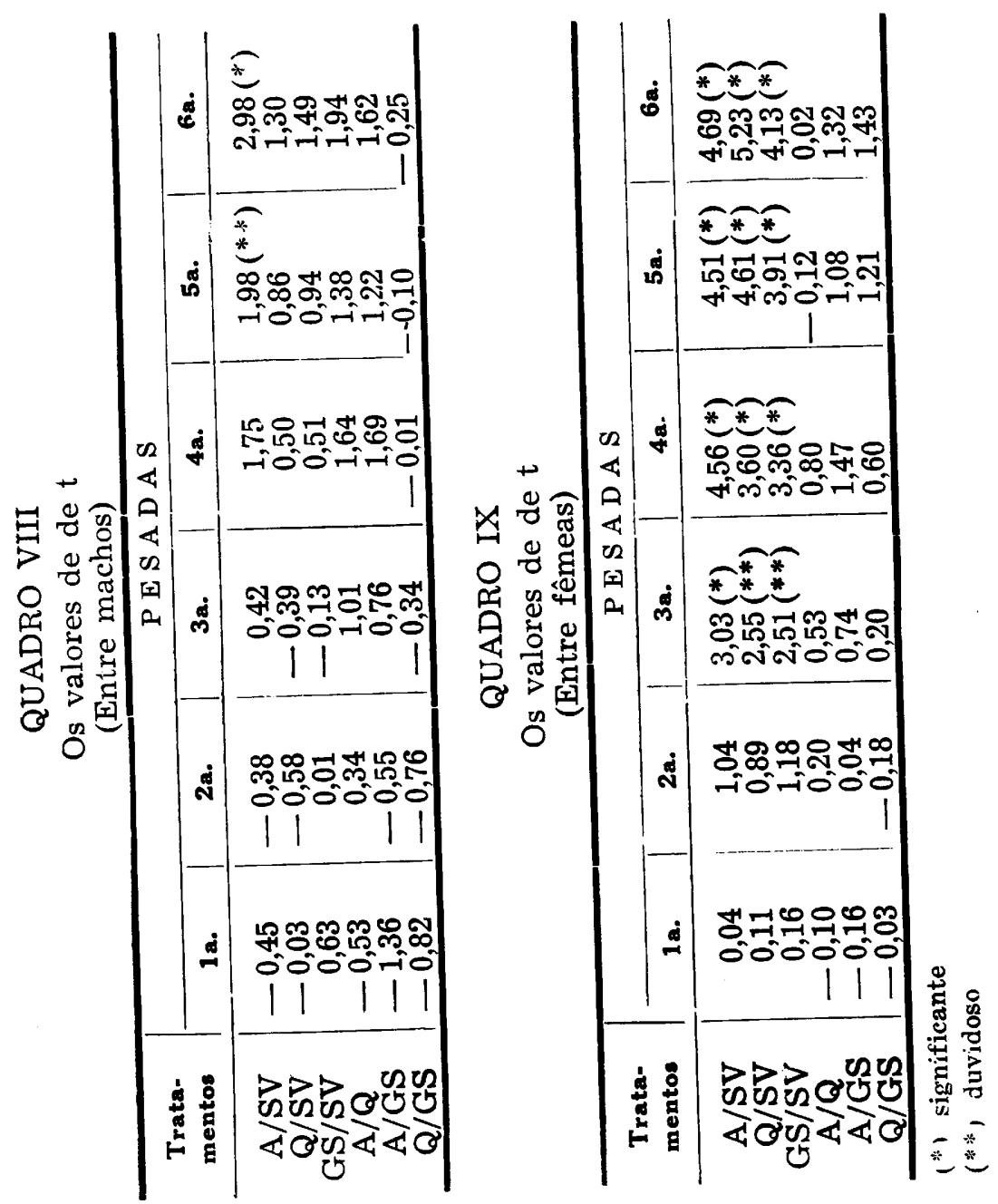




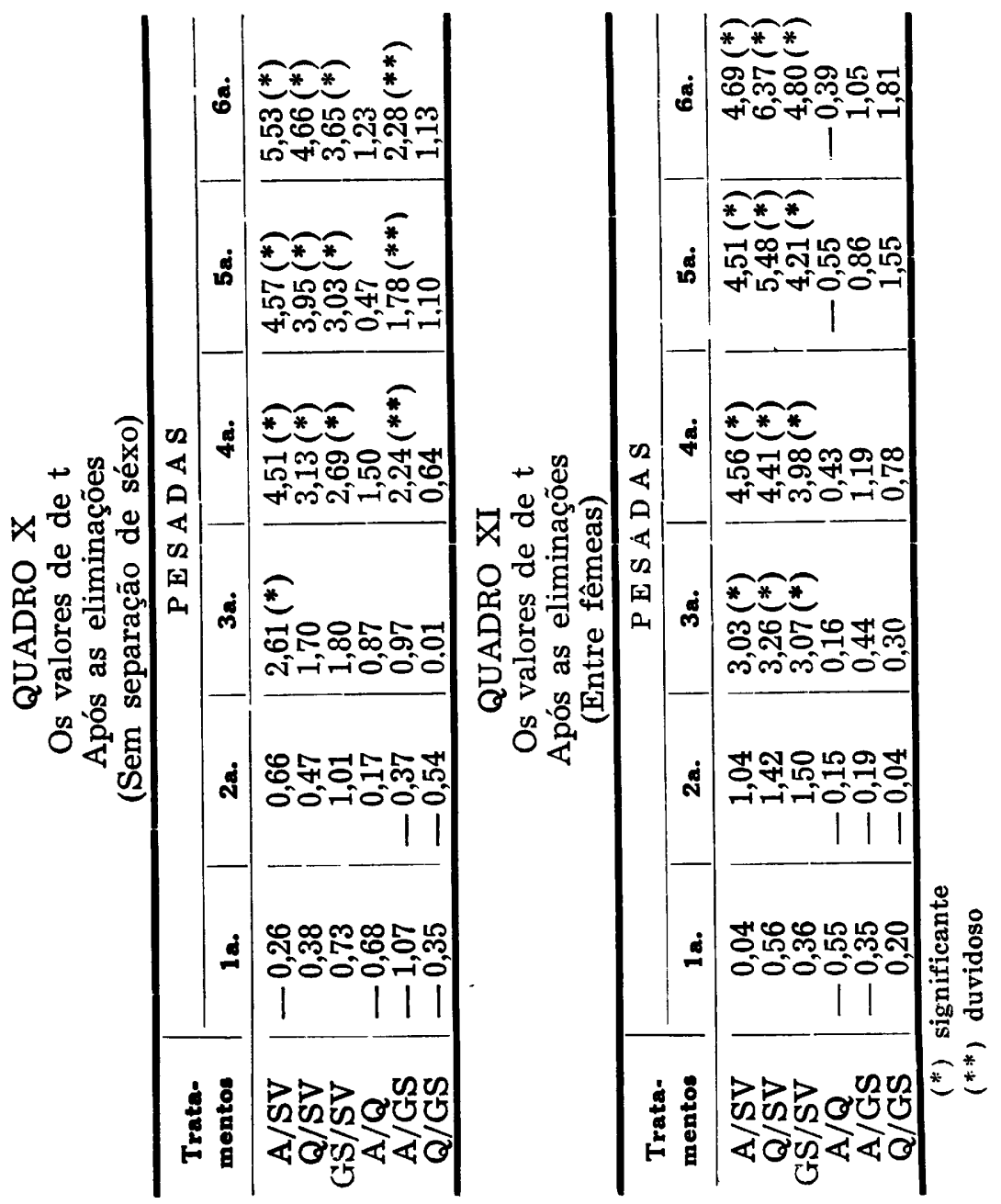

